\title{
Smart solution to detect/prevent bridge accident
}

\author{
Yousuf Yaqoob Al Shaibani, and Khoula Al Harthy \\ 09f5134@mec.edu.om, And Khoula@mec.edu.om
}

\begin{abstract}
Due to increasing and expansion of logistics in Sultanate of Oman, transportation becomes one of main support for logistics in country. The height vehicles accidents become a serious issue that have huge impact on infrastructure and human lives. As the number of long vehicles increasing the over height accidents become more and more. The aim of this project is to propose a smart-solution to minimize the accidents/collision of vehicles over height that crosses the bridges and intersections in Oman. The vehicle driver can be notified by smart solution about his vehicle status. The system is proposing smart alarming solution to minimizing number of accidents and its effect. Also, by using smart system it will be easy to investigate current method to detect the accident and evaluate the proposed solution.

The design of the system is to IoT to build complete system can detect the vehicle height and warn the driver before reach the bridge. Passive infrared sensor, IR sensor will detect the height and motion of vehicles before cross the bridge or intersection. And will send a mail or SMS to the cloud to inform the relative authorities. An Arduino is used to program and control the system. On the other hand, CCTV is taking place in system by recording and capture plate number of over height vehicles. The data gathered from the system are stored and backup kept in server whenever required. Different types of methodologies have been chosen and applied in the system are Modified waterfall, Agile, and waterfall methodology. Modified water fall methodology selected as it has different strategies that will assist in managing the challenges in case they come up and maximizing the utilization of resources and time. The system is help full to reduce the over height accidents and it will be effective for ROP and Ministry of transportation and communication for study purpose and data gathering.
\end{abstract}

Keywords: Accident, Solution, IOT, Detect, Vehicles

\section{Introduction}

The effects of large vehicles on bridge Structures is terrible problem in this days, especially in development country. However, most of road relative authorities has focused on vehicle weights only but they missed another big problem which is height of vehicle. The reason behind all these problems is commercial vehicles that are exceeding the height limits, ignoring regulations, instructors and clearances that come from the responsible authorities like ROP and Ministry of transportation and communication.

Now a day's technology and usage of smart devices has become one of the most recent ways in the world in which can be used to simplify people lifestyle and play an important role of it. Moreover, these instruments and devices can be helpful in collecting data, analyses and display the results by using sensors, logarithm, display, etc. The main idea of this project is using smart system which will be used to identify the allowed truck height should cross through bridges and intersections.
In Oman, trucks are commonly used for transportation of cargo. However it has potential to collide with the bridges and causes accidents, so by this technology the over height accidents can be minimized.

There are various types of road accidents that become a serious problem and damaging the infrastructure. The over height vehicles collisions with highway bridges and intersections that causes structural damage, injuries, and sometimes even fatalities can be eliminated or minimized by using the technology that helps to protect bridges and avoid accidents. The detection of over height vehicles before starting to enter the intersection is to avoid over height accidents in order to protect the structure of bridges from the collision of high vehicles and thus damage the bridge structure.

By using of IR sensor, height of truck can be detected and for over height vehicles, alarm and LED scree shall be activated to the driver warning him not cross the bridge or intersections. When there is alarm, the driver shall not pass through the bridge and he shall bypass the bridge through other road. CCTV system shall be provided to monitor reliability of the system and behavior of the drivers. 


\section{Journal of Student Research}

\section{Problem definition:}

Oman is witnessing a remarkable development in the logistics sector through the government's tendency to diversify sources of national income. Therefore, cargo transportations through local road networks are increasing respectively. Oman government has issued rules and regulations to control the traffic through the road networks. One of these conditions is that means of transportation height should be suitable to cross bridges. However, determining the height of tuck might be a challenge for the drivers. The uncertainty in identifying the truck height is leading to a collision with the bridge. The consequences of the collision are quite high. Moreover, Oman considers this type of accidents as a serious problem and too costly. Another consequence is that collisions lead to loss of properties, which can cause Impede the transportation operation. For example, losing means of transportation directly affect the operation. In addition, the properties can be the shipment or cargo itself and therefore it consider as loss. Additionally collision always cause traffic jams. In general, traffic jams disrupts the interests of the Oman. Moreover, collision might lead to damage the bridge or one of its annexes.

Cost of repairing of the bridges is coming with high financial impact to Oman due to high specifications it was made. Lastly, frequent collision affects the reputation cargo transportation in Oman and in which it results negatively to overall logistics sector. Another thing is that, the costs of building girders and other resources needed for repairs are expensive considering that it must be bought every time overweight vehicles hit the low clearance bridges. Moreover, a lot of taxpayers' money will be used without any strategic plans and alternative options that could minimize the expenditure. Another negative impact is the fact that these roads have to be closed for days for the repairs to continue. This will slow the economy since the vehicles have to divert to another route, which might be longer compared to the usually unknown route. Cargo destined for the port will have to spend more time on the road while the businesses will delay in the process. Also, when collisions happen, drivers can lose their lives if the impact of the accident is strong. In addition to this, the vehicles that could be following the trailers will hit them from behind if it was moving at a high speed. It can be a catastrophe if it is a highway, which will put many families in emotional distress if they lose their loved ones. If these accidents are fatal, there are socioeconomic impacts like the costs of long-term care, welfare loss and hospitalization to the victims. Increase in road accidents affects sectors such as health and planning. There will be an increase in expenditure when the accidents keep increasing considering that the costs of treating the victims might be high. As a result, the government will be at a loss because it will have to allocate more funds on health sector, which will not be a good strategic move. Thence, the best way is to ensure that there are systems on the roads that will minimize these accidents significantly.

Another thing is that, the drivers might face legal consequences or lose their jobs for negligence on the roads. If these accidents are fatal, the companies will lose their labor force, which will affect their normal operations if the drivers were already experienced and diligent in their work. A loss of skilled drivers leaves gaps that are not easy to fill. This situation must be solved early to avoid such cases happening. The employers will pay a steep price when they lose the property on the roads especially on vehicles and cargo damages. Thus, If the cargo delays, their clients will question their business dealings and will lose their market for goods.
Fourth Middle East College Student Research Conference, Muscat, Sultanate of Oman

Subsequently, this will not only affect their businesses but the country as a whole in terms of the economy. Furthermore, they have to compensate the victims and their employees for these accidents that might be fatal. Finally, frequent collision affects the reputation of cargo transportation in Oman and in which it results negatively to the overall logistics sector.

\section{Current solution:}

The over height accidents have limited solutions to reduce or avoid it from happening. As of now, Sultanate of Oman still not installed a smart system to avoid occurrence of over height vehicles accidents. ROP and Ministry of transportation and communication have limited control to warn drivers about crossing height limit. Warning sign boards are installed at every intersection and bridges identifying the allowed height limit to cross over. The same is applied for places such as, basement parking and at malls but there is an extra part is metal bar before every entrance in case driver didn't notify the height limit or crossed the height limit. This bar can result in very serious accidents and can reach to fatality and huge damage of vehicle and intersection. The cost of repairing are high and all above issues can be avoided by installing the system.

\section{Literature review:}

Literature review consist what and why a smart solution is needed in detecting and preventing collisions by the over-height detection system. Monitoring and detection of accidents work using my proposed system and how the number of accidents and their impacts are reduced will be explained. This essay will also cover how the drivers of over-height vehicles are notified about the vehicle status. It will also explore how technology plays an important role as one of the smart system solutions and how to implemented and how the IOT works in minimizing accidents by infrared sensors.

One of main topics to be conducted is the feasibility study of this project. A feasibility study is conducted to determine the mode of operation in a project, identifying the alternatives, defining requirements and evaluating the course of action. It forms a critical part in delivering the project as required. In my project, it will be evaluating the technical and financial aspects of the project and how easily it can be successful to complete with a specified time. The basic issues that seek to achieve in this smart solution system are the minimization of accidents associated with the over-height detection system. It will address the project scope in a definitive and purposeful way to identify some of the issues that need to be addressed. In feasibility study, an SWOT analysis will be created for the project whereby it will identify the strengths, weaknesses, opportunities, and threats of the system that will create. Next is to address the technical feasibility in which it will highlight why this system will be a success in Oman. Economic feasibility will also be covered to understand the benefits of this project to Oman. Making a decision based on the economic feasibility is dependent on the cost-benefit analysis which will involve the whole process of purchasing the system to its installation on the roads. It will also do a cost analysis of the important components that will be vital in accomplishing this project. This will be presented in terms of the estimated budget and highlighting their roles in the project. Operational feasibility will also be necessary for assessing the capability of the system in solving the issues of overhead collisions in Oman. In the same time, it will also cover whether the project is tangible or intangible. Tangible benefits are measured in monetary terms. The transport sector is a major component through which economic activity takes place. These are benefits that can't be quantified in monetary terms or measured with certainty. The 
introduction of the over-height detection system contributes a lot of intangible benefits to the government and the public in general.

\section{What is a smart solution?}

Many studies have been done to identify the cause of accidents for over height vehicles in the past. Scholars have come up with theories and case studies that explain how off shelf systems are significant in minimizing and eliminating collisions of overhead vehicles and the roadway bridges. In most cases, their reports have recommended relatively inexpensive methods that can be implemented by the transport departments and the police Highway Administration. They have shown how each system can be beneficial based on the desired results. According to many research studies, the systems ought to focus on user needs by effectively detecting vehicle heights, therefore, reducing accidents on low clearance bridges. In this project, It will be addressed the literature review on important points related to the project. First will be to cover the definition of the smart solution in detecting the accidents utilizing the infrared sensors especially by over height vehicles. Currently, many statewide bridges are susceptible to collisions with over height vehicles. What is more worrying is the lack of a nationwide database on over height collisions. However, surveys have been done by many states and the findings from the 29 states indicate that the over height collisions is a major problem. The structural damages caused have a huge impact on the police and state governments' budget and disruption of traffic due to the closure of the road networks for temporary repairs. Most states would want to avoid the constant outflow of resources that are spent on repairs of the bridges. Scholars have proposed various cost-effective and efficient methods that will assist in warning over height vehicles of imminent danger on the roads.

Currently, the methods that have been found to be effective include the multi-based systems, camera-based systems, and laser-based systems, signage systems and systems that are installed on a vehicle. A number of technologies have been studied by many scholars to be effective in-vehicle detection nowadays on the roads, for instance, the inductive loops, vision-based, acoustic-based infrared and piezo-electric technologies. It's important to focus on what scholars have found out about the use of over-height detection system which is made up of Infrared range (IR) distance sensor, Arduino, License plate recognition (LPR), liquid crystal display (LCD)/LED, a server, and alarm buzzers as a method of detecting and preventing collisions of over-height vehicles on roadways bridges.

Stephen P. Mattingly conducted a study to examine the warning devices that are used to evaluate over-height vehicles in June 2003 for the department of transportation and public facilities in the state of Alaska. Mattingly describes the smart solution to detect over height vehicles using infrared sensors as a method that involves the alignment of infrared beams at a threshold of fourteen feet across the inbound lanes. He found that an automatic alert will be sent in the form of an email, video or texts to the roads authorities of an imminent violation of the threshold height by a vehicle. Flashing beacons will also be seen by the driver as a warning due to the automatic activation from the infrared sensors as it detects the vehicle from a distance. Mattingly's anecdotal research shows that Glenn Highway in Anchorage Bowl has been struck many times by the over height loads especially on the Eklutna interchange bridge. He gives an account of how the Alaskan has spent a lot of their resources in repairing the concrete girders. The repairs are very expensive and cause a lot of disruption on the roads forcing the vehicles to be diverted to the interchange ramps. Mattingly found out that the department of transport knows about the use of infrared detection as an effective method of alerting and rerouting the over height vehicles but are adamant in using it because of the extreme weather conditions. Mattingly concludes that they don't have enough information regarding the effectiveness and the smart solutions that infrared detection offers in warning over height vehicles against colliding with the bridges.

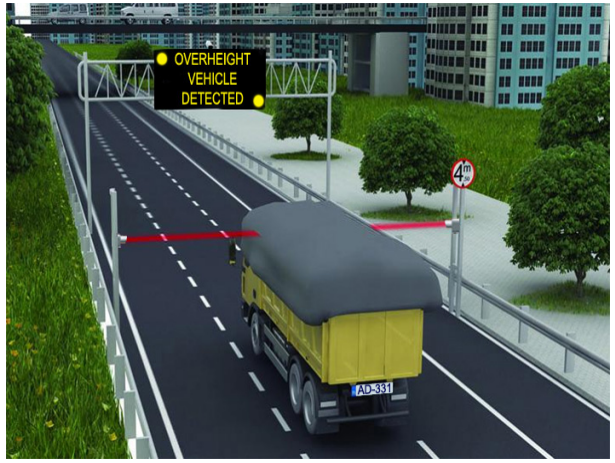

Figure 1. A truck passing through the OVDS (Sun et al. 2013).

The professors of Georgia Southern University also did a research project to evaluate warning systems that are effective in overhead clearance detection. Marcel Maghiar, Gustavo Maldonado and Mike Jackson were contracted by the Georgia Department of transportation to provide recommendations on how to minimize collisions of overhead vehicles against the Georgia low clearance bridges. In their report, the professors describe smart solutions using infrared to detect overhead vehicles as an important warning system. They use the case of Houlihan Bridge to demonstrate the need for infrared sensors in minimizing the imminent threats of collisions. According to their findings, 50 collisions were reported each year along the Houlihan Bridge. The bridge had to be closed due to the structural damage that had been caused constantly by the tall vehicles. The professors were tasked in conducting an investigation on the most cost-effective and efficient warning system that will reduce the accidents at the low clearance bridges across the state of Georgia. Their research focused on reviewing the existing systems that the state had installed for instance the signage and remote sensing devices. They also compared with what other states were using to solve the issue of accidents by tall vehicles. In the research, the found out that Florida prevented the collisions using dual infrared beams to detect the approaching vehicles. The staff manning the detection system recommended the designing of a similar system by other states with the approval of the traffic operations engineers. Another State they found to be using infrared sensors is Minnesota. According to their research, the infrared system in Minnesota is active and works by transmitting infrared light to the receiver when a tall vehicle is detected. They describe that the use of infrared in Minnesota works when a beam is blocked by an object moving in speed of between 1 and $120 \mathrm{~km} / \mathrm{h}$ whereby a buzzer black sensor is triggered to produce sounds. The diameter of the object should be either 3 inches or above to achieve a full blockage of the beam. In addition to the buzzer sounds, they found out that once the object is detected there are yellow beacons that will flash on the warning signs for the drive to make the right decision due to an imminent danger. 


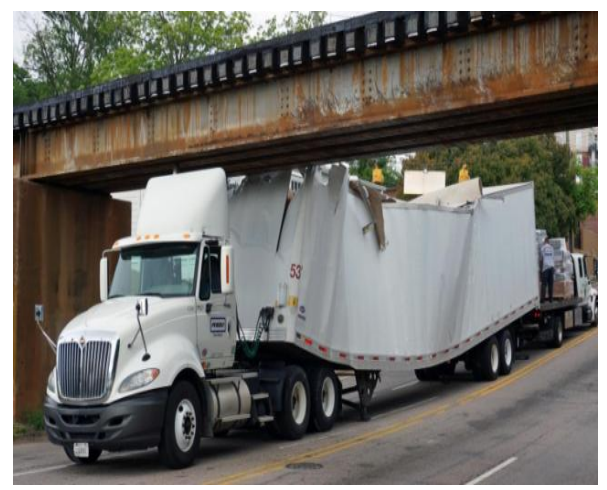

Figure 2. An accident occurs involving an over height tractor trailer (Gutierrez and Helsel, 2016)

According to their study, they found out that this technique is rarely used by most states due to the high level of technical expertise needed to operate these devices. However, most states appreciate their cost-effectiveness and will likely be adopted by many states. They found that the united States in making a lot of progress in IT solution to improve non-intrusive methods like the use of infrared sensors.

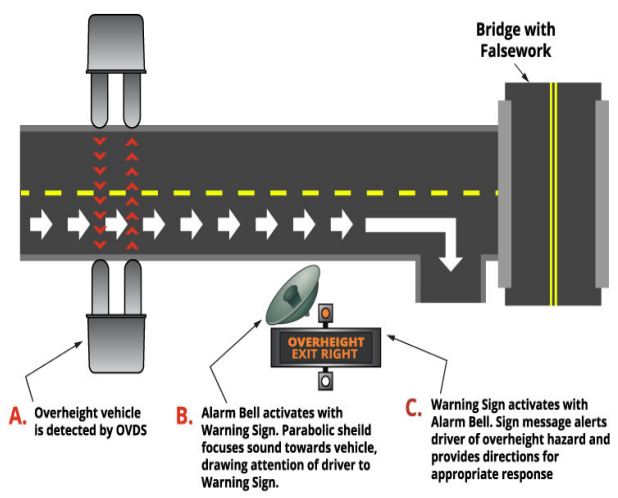

Figure 3. How the detection system works (Mimbela \& Klein 2007).

\section{Why we need smart solution?}

According to their research, they describe passive infrared sensors to be efficient in detecting vehicles through the emission and reflection of the radiation coming from these objects. These types of sensors are required especially by the department of transport in collecting information relating to a vehicles presence, passengers in the vehicle and its speed. It will be easy to track the height of the vehicle against the bridge ahead and therefore send an alert warning to the driver. The journal also examines active infrared sensors which utilize laser diodes or light emitting diodes in detecting the reflection time of an object. The authors state that these type of infrared sensors are needed in assessing the vehicle's classification, flow volume, the speed of an overhead, vehicle traffic density and the presence of an overhead vehicle, therefore, minimizing collisions against low clearance bridges.

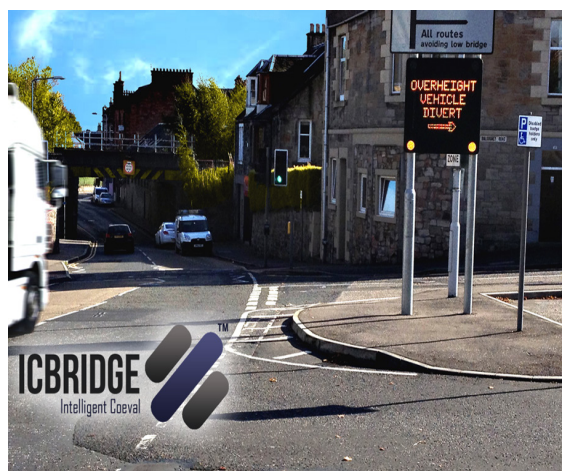

Figure 4. Warning signs requiring a driver to take another route (Highways Industry 2019)

Marcel Maghiar, Gustavo Maldonado and Mike Jackson state that the infrared sensors were needed by the department of transportation in Georgia to minimize the number of collisions that had been increasing especially at the Houlihan Bridge. After completing their research they concluded that the infrared sensors were vital to most of the departments of transportation in the United States need these sensors for traffic planning. Other useful uses of these sensors involved the estimation of truck volumes, determining minimum clearances and used on movable bridges among many other applications. They realized that most of the transportation agencies have acted swiftly in adopting preventive mechanisms that would simultaneously the safety on the roads by minimizing the costly accidents.

Luz Elena Y. Mimbela and Lawrence A. Klein presented a presentation to the Federal highway administration on their views on surveillance technologies for use in vehicle detection by the transportation department. They examined these technologies to recommend smart solutions needed in solving accidents caused by vehicles. Mimbela and Klein note that the active and passive infrared sensors are very important in traffic applications especially in signal control. According to their findings, the sensors are usually mounted overhead to have a better to clearly detect approaching and departing vehicles. Most roads can have modern laser sensors which are installed in road intersections to transmit and receive vehicles signals. They illustrate that infrared sensors can also classify vehicles based on the detected axles coming from the vehicles. They also describe the advantages of these sensors, for instance, its ability to transmit multiple beams. This, therefore, makes it useful in measuring speed, class, and position of the over height vehicles. Mibela and Klein also suggest that AS 800Series passive detector is very efficient because of its high sensitivity. They state that motorcycles and tow bars can easily be detected but the classification of the overhead vehicles will depend on their characteristics (Mimbela \& Klein 2007).

Korssen of the Herald sun did research about the rail bridge at Montague Street in South Melbourne Australia and discovered a worrying trend in the number of accidents that had been experienced there. In the report, Korssen states that 102 collisions had happened at the bridge for the past 6 years. The reports of the notorious crashes at the Montague St. Bridge were backed up by The Age Newspaper that reported a crash by a bust on the same street whereby 14 passengers were lucky to evade a fatal accident. Charley Hannagan who is a journalist for the Post Standard in New York reported a crash of the double-decker bus on Onondaga lake parkway in 2010. According to Hannagan's article, the driver failed to adhere to the flashing lights from warning signs leading to a collision with the 10 -foot 9 inch railroad bridge. The accident was fatal and 4 people reportedly died while 24 others suffered serious 
injuries (Hannagan, 2010).

Bowman (1993) highlights the basic reasons why infrared sensors are needed by examining the vertical clearance to install the devices to warn the drivers. He states that the infrared sensors when placed at the right position are effective in reducing the frequency of bridge crashes. He identifies the active detection and warning system to be the preferred devices that are installed to verify where the vehicle is and has detector loops to prevent any false activation.

Weil, Wootton, and Garcia-Ortiz did research on the applications of infrared sensors on monitoring incident on the roads. The researchers suggest that the sensors are very useful in the surveillance of roads. They also found out that the traffic engineering community has put more attention on sensor performance primarily on achieving accuracy. They state that timely detection of unscheduled accidents is an important problem that is common on urban freeway traffic operations. The images of an accident or breakdown of a vehicle can be relayed to a traffic control center automatically by a high way incident detection system. Their study indicates that they work by recognizing any traffic anomalies on the highways based on the lanes, occupancy and spend of the vehicles. The transport system in the U.S wanted a technology would replace the inductive loop by solving all needs on the roads. Passive infrared and CCD sensors were the best choice according to the researchers. The two technological sensors were very vital in viewing the uncongested and rush-hour flow of vehicle movement. Their findings suggest that the infrared sensors work best on areas that are subject to foggy conditions, for instance, the coastal areas. (Weil, Wootton, and Garcia-ortiz, 1998, 264).

Maghiar and his fellow professors describe the CCTV cameras as a very effective part of an over-height detection system. They give a case study on how the state of New York, especially in Hudson Valley, Syracuse, and Long Island, implemented the vehicle height detection systems that could be activated when a laser beam is broken. The main objective of installing this system In New York was to deal with trucks that entered the Parkway in Hudson Valley and Long Island. Maghiar and his colleagues state that many programs have been included by the Department of transport in New York like the CCTV cameras, over height optical detectors and electronic variable message sign. They explain that the CCTVs work by capturing a video of an over-height vehicle when the system is triggered. The operations center is then notified while the driver is warned by the variable message sign on the restrictions about the height of their vehicle. This is the time that the police agency is informed for the officers to be dispatched to the site. (Maghiar et al 2017).

This will provide clear information of the vehicle about an imminent accident that it might cause if it is over speeding especially if there is a low clearance bridge ahead. According to their research, a prototype sensor system using a photodetector and laser diode was developed and tested by projecting the laser directly to the photodetector.

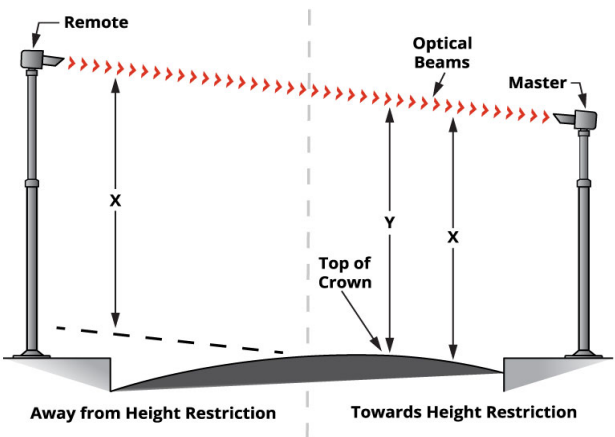

Figure 5. Optical beams sent by the infrared sensors to detect an object that nears the bridge (Mimbela \& Klein 2007).

Dormer report for CBC news in 2016 indicates how the infrared sensors worked to stop accidents on the lower clearance bridges. When Dormer interviewed the Toronto city spokesperson, Tara Norton-Merrin, she explained that the infrared light will flash when the sensors detect an oncoming over-height vehicle. She also said that a big screen is installed at the bridge or Plus 15 that notifies the driver that the vehicle's height is above the required limit to pass under the bridge. She notes that a responsible diver will need to stop and take an alternate route to avoid crashing onto the bridge. The spokesperson for the city of Toronto continued to state that, there have been no serious incidents when the trucks get stuck under the bridges but there are negative impacts on the traffic when trying to remove them. Dormer discovered a warning system at the Center Street Bridge in Toronto whereby the Spokesperson credits it reducing the number of crashes. She notes that in 2015 the bridges got hit 15 times while the Plus $15 \mathrm{~s}$ were crashed into by trucks three times in Centre Street Bridge accounted for the 10 incidents. Norton-Merrin credits the savings around of 120000 RO made annually to the installation of detection units on the bridges. She also notes that the installation and maintenance only cost them around $58000 \mathrm{RO}$ which was way cheaper as compared to the repairs and maintenance that could have resulted from crashes by the trucks.

Hoa Nguyen highlights how the infrared sensors work in notifying the driver about the status of their vehicle. He gives an example of interchanges near the Hutchison River Parkway. He discovered that there is a big electronic billboard that alerts the driver to stop for the police check up. According to his article, the over-height detection system was opened in 2014 opened by Governor Cuomo. This detection system uses infrared sensors to detect overhead vehicles as they approach the four ramps from Westchester Avenue. The system was installed because of the low hanging bridges that might be hit by the trucks as they try to enter the parkway. Nguyen indicates that in addition to the billboard warning the drivers to pull over, the detection system will send an alert to the traffic management center if the driver violates against the warning. The traffic center will in turn contact the Westchester County police to stop the over height vehicles from entering the parkway (Nguyen, 2015, 1).

After conducting his research, Nguyen says that the state spent around 390.000 RO million in installing the system as part of the safety measures for the vehicles. Another point that Nguyen discovered is the fact that The Hutch has a low bridge clearance because the initial designing was meant for small cars only. If trucks enter the parkway, they will crash on the bridge or get stuck resulting in traffic congestion in New York City. 


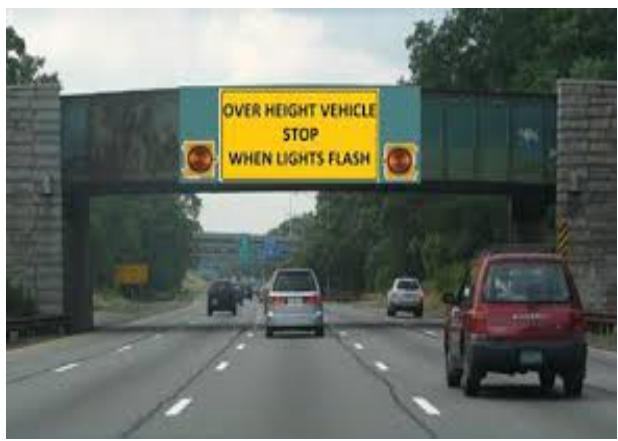

Figure 6. Billboard reminding drivers to stop when the flashlights are activated (Geyer 2014).

Professor Patnaik and one of his student also notes that a driver can be notified about the over speeding vehicle using the infrared sensors. According to their research on classifying and measuring the speed of vehicles, they note that the rapid traffic demand measures have prompted many transportation departments to apply intelligent technological systems in ensuring safety on the roads. Infrared is one method that they suggest to be effective in detecting the speed of a car which then notifies the driver to slow down (Patnaik \& Kumar, 2016, $1)$.

Mimbela \& Klein (2007) also outlines the use of infra beacons to notify drivers of the vehicle's status. The transmitters are fixed on the vehicles and upon arrival of a vehicle to the intersection; an infrared signal is received and validated for the vehicle to pass. They state that this is a type of a receiver device that will flash on and off when it detects vehicles of different heights. According to their findings, intersections are installed with these beacons to distinguish between emergency and transit vehicles that should be allowed to pass. The infrared light is activated when the vehicle is allowed to pass and when there is light then the vehicle can't pass through the intersection for safety reasons.

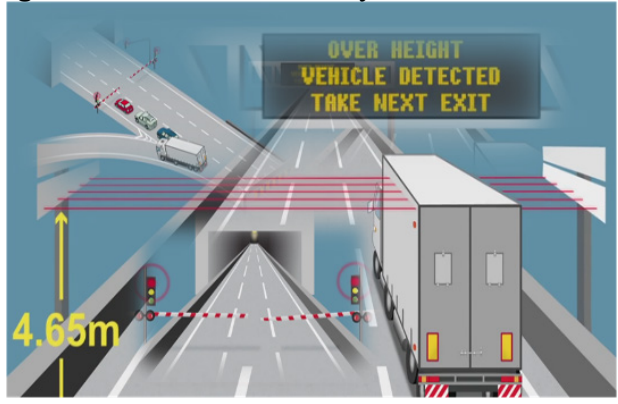
2014).

Figure 7. A driver changes route after the alert (Geyer

Maghiar and his fellow professors identified the new technology that was being sold by the Trigg industries. In their judgment and the findings of the research on the collisions on Georgia highways, they concluded that the infrared sensors would be a better recommendation they would give to the officials to be installed in warning drivers against danger. Trigg industries had provided solutions to 12 states out of the 24 which were using the warning systems. After conducting a literature review on a couple of documents, the professors proposed systems that would use the laser-based detectors to trigger flashing signs. Some factors like costs and the best location to install the new technology were to be taken into consideration by the department of transportation in Georgia
Fourth Middle East College Student Research Conference, Muscat, Sultanate of Oman

(Maghiar et al 2017).

Sharma and Hurlebaus (2012), state that low clearance bridges are commonly hit by over-height vehicles which can cause fatalities and injuries to the passengers and the driver. They also state that these collisions damage the bridge girders which cost a lot to repair and time-consuming. They attribute the damages and fatalities on over height vehicles (Sharma \& Hurlebaus, 2012).

They also believe that these accidents and its related effects are expected to rise if the new technology is not adopted as one of the smart solutions for safety and prevention mechanism. Berton and his colleagues highlight the benefits that come with the new technology as one of the smart systems in addressing the issues relating to safety on the roads. They believe that road safety is compromised when the over height vehicles like tipper trucks and exceptional convoys collide on highway and pedestrians bridges causing fatalities and major economic losses. They appreciate the fact that several studies have been conducted on reducing the probability of occurrence especially by proposing the installation of the impact detection systems, static road signs and the use of steel pedestals (Bertona et al., 2017).

However, despite these mechanisms they believe more has to be done because the bridges are continually hit by the heavy vehicles due to the densification of the road networks.

\section{Methodology:}

Product methodology will be vital in structuring, planning and controlling the steps to be taken in developing the over-height detection system. It will provide more details which will be needed during the process such as the requirements, designing, testing, etc. an important point to be considered while developing the product is the fact that this is an innovative idea and therefore it must be aware of the constantly changing technology. Some of the methodologies that have been chosen are Modified waterfall, Agile, and waterfall methodology. They have different strategies that will assist me in managing the challenges in case they come up and maximizing the utilization of resources and time.

\subsection{Modified waterfall:}

Modified waterfall is a software development model whereby the process is sequential and there is a steady flow of phases. The flows of phases are in form of a waterfall. These phases include the requirement analysis, design, implementation, testing and maintenance. One phase must be completed before moving to the next one. There is no turning back once the project moves to the next phase. The creation of an over-height detection system to minimize the accidents on the roads requires a continuous lifecycle of services to complete the tasks on time. This model is chosen for this project for the following reasons:

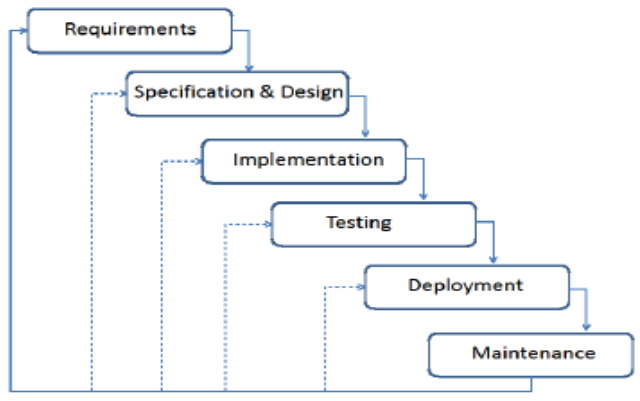

Figure 8. Modified waterfall methodology (Gao \& Hembroff 12). 


\section{Data analysis techniques:}

Data analysis falls into two categories which are qualitative and quantitative data analysis. Qualitative data analysis seeks to contribute to a better understanding of a context by generating rich and valid process data. Quantitative analysis generates quantified or population-based data to establish the cause and effects of a phenomenon under study. The techniques used in each category vary.

The data analysis was necessary for defining user expectations for the system. It is the basis for evaluating the stakeholders' needs and communicating to them in a language that they will understand for instance the use of excel charts and graphs for quantitative analysis and the use of content analysis, narrative analysis, discourse analysis, and grounded theory, etc. The techniques used in requirement analysis maps the workflow or process.

After conducting interviews and presenting the participants with a list of questionnaires to give their views about the IoT networks in delivering smart services, analyzing the data using charts and graphs as shown below while providing a qualitative analysis based on the observations made on the graphs. This data analysis is based on 50 respondents who managed to answer the questions clearly.

\section{Questions:}

Do you believe that the IOT has helped in minimizing the accidents on the roads?

\section{IoT has helped in minimizing the...}

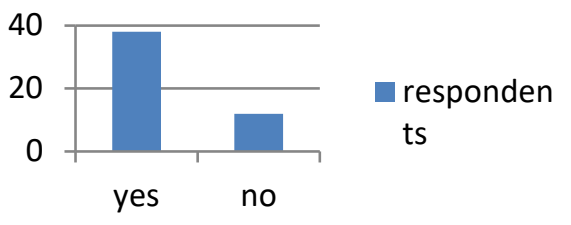

Figure 9. Based on this chart, it is clear that man believes that the IoT stands a better chance of minimizing the increase in accidents.

Do you believe more has to be done to improve safety on the roads?

\section{More has to be done to...}

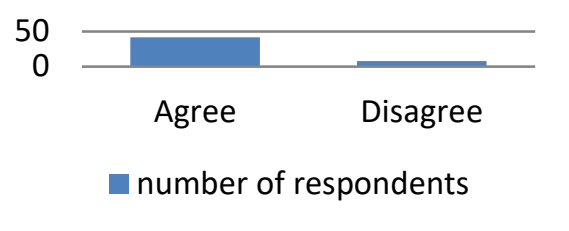

Figure 10. On this graph, the respondents want a lot of efforts to be put in resolving accidents issues in Oman.
Has the government done enough to solve the traffic issues using the IOT devices in Oman?

On a scale of $1-5$, how will you rate the work performance of the IoT applications as one of the smart solutions in the transport sector?

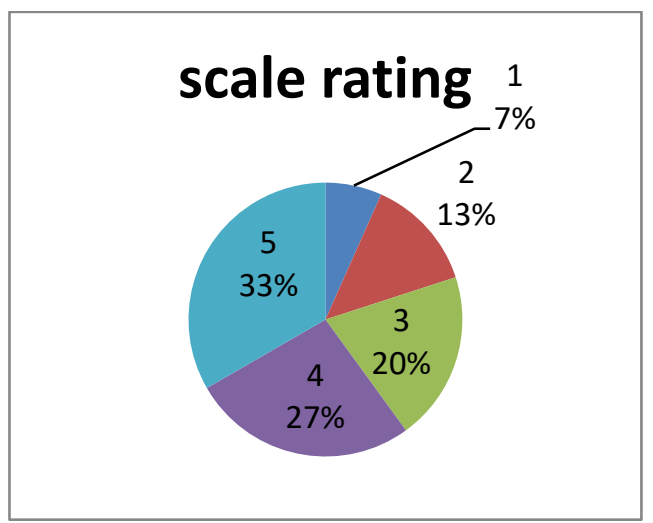

Figure 12. In this chart, it is clear that a majority which is $33 \%$ highly rate the functionality of the IOT network.

Between the IOT technology and the police, which resource is likely going to improve safety on the roads?

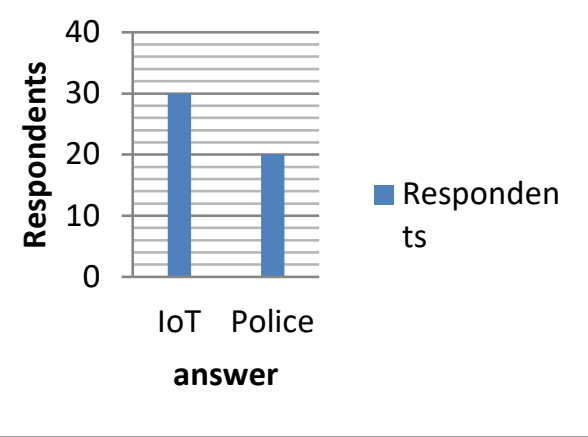

Figure 13. Based on this graph, a majority of the respondents believe that IoT is effective as a smart solution in resolving traffic issues as compared to the police.

\section{Logical diagram:}

The network is made of different layers where every layer is lever and part of the full network. The numbers and the types of the layers can be changed according to the requirement of the project and the interfaces needed. In this project will have four different layers, WAN Interface, Edge IOT, Sensors \& devices layer. The first layer is the Web App Interface, which is the user and internet connection interface. In this level of the network all the users will camp on and the public network connection. The second layer is the WAN

Interface where all the wireless interface between the project and the user. The third layer is the project controller level and the interface to the internet gateway. This layer contained the Arduino as the controller of the project and the WiFi model to be the interface between the project and the user. This layer is the main layer of the project. As it's the connection and controller of the project components. 


\section{Journal of Student Research}

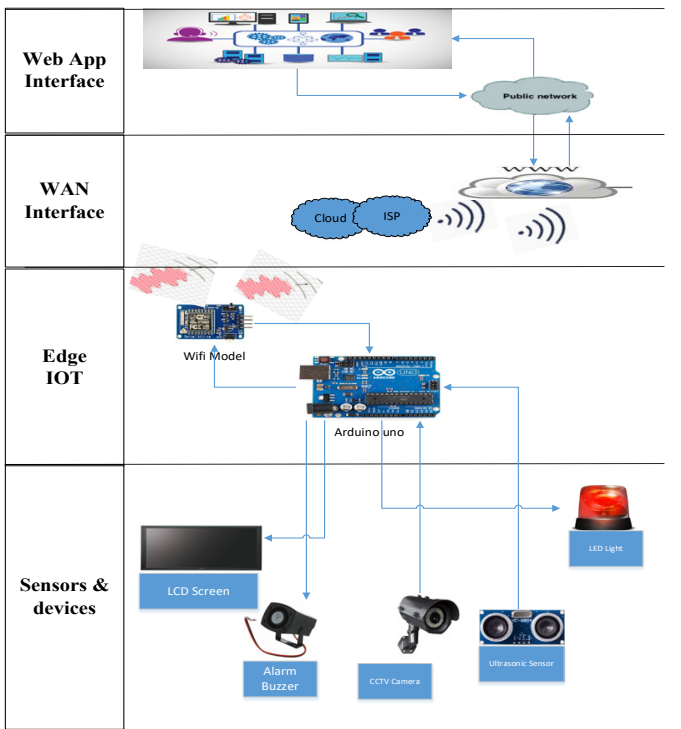

Figure 15

Finally, the last part of the project and the last layer is the Sensors \& devices layer. This layer is the last layer of the project, which has all the sensors and devices of the project. At this level of the project there are five components staring with the sensor to identify the level of the truck to send it to the controller. Then the screen, light, and buzzer to notify and inform the driver. Lastly the camera to record and show the user the situation.

\section{Physical diagram:}

Physical diagram is showing the components of the project physically and its location in the real installation. In this project, the components will be installed at the road as the figure 16 is showing.

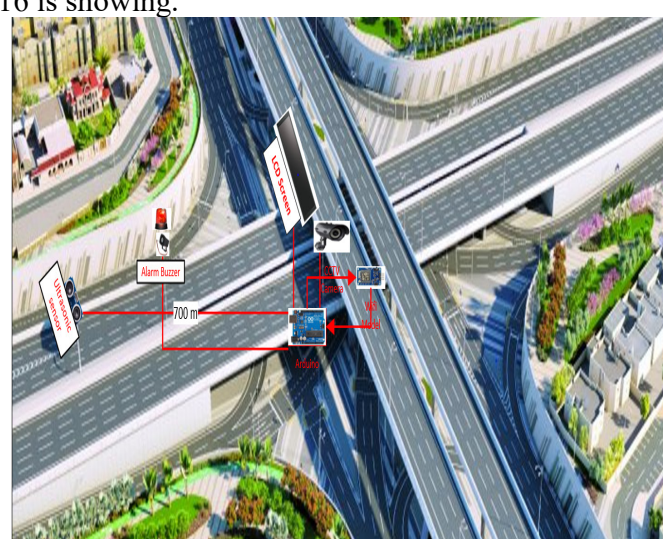

Figure 16: project Physical diagram

The figure is showing the location of every component of the project. All the components of the EDG IOT \& Sensors \& devices layers will be present at this diagram. As shown at the figure the screen will be at the top of the bridge to be seen by the driver. The camera as will be at the same location to get the full picture to the user. The controller and the WiFi model will be located under the bridge to be protected. Finally, the sensor will be $700 \mathrm{~m}$ from the bridge and the LED light with the buzzer will be $500 \mathrm{~m}$ from the bridge. This is to get the information about the trucks early, which is giving the chance for the driver to go out from the rood.
Fourth Middle East College Student Research Conference, Muscat, Sultanate of Oman

\section{References:}

1. SUN, Z., BEBIS, G. \& MILLER, R. (2013). On-road vehicle detection using optical sensors: A review. Dearborn, MI.

2. GUTIERREZ, G. \& HELSEL, P. (2016). North Carolina 'Can Opener' Bridge Continues to Wreak Havoc on Trucks. Retrieved from:https://www.nbcnews.com/nightly-news/north-carolina-canopener-bridge-continues-wreak-havoc-trucks-n492511

3. MIMBELA, L. E. Y., \& KLEIN, L. A. (2007). A Summary of Vehicle Detection and Surveillance Technologies use in Intelligent Transportation Systems. Las Cruces, NM.

4. MAGHIAR, M., JACKSON, M., MALDONADO, C.G (2017). Warning systems evaluation for overhead clearance detection. Statesboro, GA.

5. GEYER, T. (2014). Low truck-eating bridge snares semitrailers. Davenport, IA. The Quad city Times. Retrieved from: https:/qctimes.com/traffic/low-truck-eating-bridgesnaressemitrailers/article_6301f82d-d399-5a91-9c21-d4db3180cf26.html

6. HANNAGAN, C. (2010). Four are dead in Megabus crash on Onondaga Lake Parkway.

7. WEIL, R., WOOTTON, J., \& GARCIA-ORTIZ, A. (1998) Traffic Incident Detection: Sensors and Algorithms. Saint Louis, Advanced Development Center, Systems \& Electronics Inc.YENER, M., \& DUNDAR, O. (2016). Expert Android Studio.

8. NGUYEN, H. (2015). Hutchinson Parkway: Infrared truck sensor now in place. New York, the USA Today.

9. PATNAIK, P.K., \& KUMAR, R.T. (2016). Vehicle Classification and Speed Measurement using IR Sensor. Pradesh, International Journal \& Magazine of Engineering, Technology, Management, and Research.

10. SHARMA, H., AND HURLEBAUS, S. (2012). Over-height Collision Protection Measures for Bridges. College Station, TX. Retrieved from:

https://ascelibrary.org/doi/abs/10.1061/9780784412367.071

11. BERTONA, E., BOUAANANIB, N., LAMARCHEA, C., \& ROY, N (2017). Finite element modeling of the impact of heavy vehicles on highway and pedestrian bridge decks.

12. GAO, CHUNMING \& HEMBROFF, GUY. (2012).

Implications of modified waterfall model to the roles and education of health IT professionals. 1368-

1369.10.1109/NOMS.2012.6212076. 